\title{
International
}

\section{MENA Workshops Call For Leadership Proposals}

\begin{abstract}
PSA is pleased to announce a call for proposals from political scientists interested in serving as co-leaders for the sixth annual MENA Workshop program. The 2019 program will be conducted as a series of two oneweek sessions (held in the spring and fall) linked by a three to four month break for writing, research, and manuscript revision. For a full description of the program and application process, see the project website: http://web.apsanet. org/mena/. The deadline to submit proposals is Sunday, October 28, 2018.
\end{abstract}

\section{BACKGROUND}

Funded by Carnegie Corporation of New York, the MENA Workshops are a multi-year effort to support political science research and networking among earlycareer scholars across the region. The workshops extend APSA's engagement with the international political science community and strengthen efforts to support research networks linking US scholars with colleagues in the Arab MENA region.

Hosted in cooperation with universities and research institutions across the Arab world, previous workshops have been held in Egypt, Jordan, Kuwait, Lebanon, Morocco, Qatar, and Tunisia. Each program is dedicated to a substantive issue in political science, with a unique schedule of lectures, discussions, topical presentations and debates, guest speakers, peer review sessions, professional development seminars, and local field trips. Throughout the workshops, fellows receive critical feedback on their own research and work to refine their manuscripts for publication.

Workshops are led by a team of two scholars based at universities in the Arab world and two scholars based in the US or Europe. Co-leaders serve as academic directors of the program and are responsible for identifying universities or research institutes in the region to host the workshops, preparing a unique syllabus with readings and discussion sessions, and providing detailed feedback on participants' research. Program administration and logistics will be led by APSA staff in conjunction with local host partners. An honorarium will be provided and related expenses (transportation and lodging) will be covered.

Participants will include approximately twenty competitively-selected $\mathrm{PhD}$ candidates and post-doctoral researchers from across the Arab world. The working language of the program is English.

\section{APPLICATION INSTRUCTIONS AND CRITERIA}

Workshop proposals should be submitted jointly by the four co-leaders (two based in the Arab World and two based in the US/Europe). Leadership teams may include a combination of junior (assistant professor) and senior scholars (associate or full professor); however, must include at least one senior scholar with experience advising $\mathrm{PhD}$ candidates. Proposals should explain the scope of the professional ties between workshop co-leaders, with preference given to individuals and teams demonstrating previous collaboration.

Workshop proposals should specify, with justification, where the workshops will take place and with which institutions. Strong preference will be given to proposals that include the MENA-based co-leaders' institutions as host organizations. Local partners must present a welcoming environment for social science research and have the institutional capacity to support a successful residential workshop, including close linkages to local institutions of higher education and research communities.

Proposals should be written in three sections:

\section{Workshop Theme (1-2 pages)}

The workshop theme proposal should provide a coherent intellectual foundation for the overall program. Prospective co-leaders should specify a thematic focus and outline relevant sub-themes from which they will build a reading list and set the schedule of events for both workshop weeks. Any research topic or substantive theme in political science is welcome. Proposals should address how the theme will incorporate theoretical and methodological training, how it will incorporate new developments in the field and literature, and how it will achieve the program goals of supporting regional networking and publication.

\section{Leaders and Partners (3-4 pages)}

In this section, coleaders must provide detailed information on the following:

-Identify the workshop co-leaders and describe the professional ties between them.

- A specific division of labor among the workshop leaders.

- Proposed location and institutional partner.

- Proposing possible dates for both workshop weeks.

\section{Supplementary Info (no page limit)}

This section of the proposal should provide:

- Recent CVs for all prospective workshop co-leaders

- A discussion of any relevant experience in organizing workshops

- A draft reading list and/or workshop schedule (optional)

- A letter of support from the proposed institutional partner (optional)

\section{APPLICATION TIMELINE AND INFORMATION}

Proposals should be submitted via the online form at https://apsa.wufoo.com/ forms/2019-mena-workshop-leadershipproposals/. Submit no later than Sunday October 28, 2018. Attachments should be in Microsoft Word format, 12-point font, and double-spaced. Team selection will be announced in December 2019. Prospective leaders interested in discussing their proposal ideas and/or receiving feedback on a draft proposal are encouraged to reach out to APSA well before the deadline.

Send an email to menaworkshops@ apsanet.org if you have questions or would like more information about the workshops and/or application process. 